\title{
Interprofessional Simulation in Accredited Paramedic Programs
}

Kim D. McKenna

St. Charles County Ambulance District, kimmckenna@sbcglobal.net

Elliot Carhart

Jefferson College of Health Sciences, edcarhart@jchs.edu

Daniel Bercher

University of Arkansas for Medical Sciences, bercherdaniell@uams.edu

Andrew E. Spain

Society for Simulation in Healthcare, aspain@ssih.org

John Todaro

St. Petersburg College, todaro.john@spcollege.edu

See next page for additional authors

Follow this and additional works at: https://nsuworks.nova.edu/ijahsp

Part of the Education Commons, and the Medicine and Health Sciences Commons

\section{Recommended Citation}

McKenna KD, Carhart E, Bercher D, Spain AE, Todaro J, Freel J. Interprofessional Simulation in Accredited Paramedic Programs. The Internet Journal of Allied Health Sciences and Practice. 2016 Jan 01;14(2), Article 6.

This Manuscript is brought to you for free and open access by the College of Health Care Sciences at NSUWorks. It has been accepted for inclusion in Internet Journal of Allied Health Sciences and Practice by an authorized editor of NSUWorks. For more information, please contact nsuworks@nova.edu. 


\title{
Interprofessional Simulation in Accredited Paramedic Programs
}

\begin{abstract}
Introduction: Healthcare leaders advocate for interprofessional education as a means to promote collaborative practice, enhance interdisciplinary communication, and improve patient safety in the health professions. There is little evidence specific to interprofessional simulation in paramedic education. Methods: The National Association of EMS Educators (NAEMSE) surveyed paramedic programs that were accredited or in the process of becoming accredited. Program respondents were asked to characterize their resources and their use of those resources, and then were asked about their perceptions pertaining to simulation in their program. Chi-square analysis was used to compare characteristics of programs that participated in interdisciplinary simulation with those that did not. Results: Of the 389 of $638(61 \%)$ paramedic program survey respondents, 44\% (159 of 362) report interprofessional simulation. They perceived they used the right amount of simulation more frequently than other paramedic programs $X^{2}(1$, $N=362)=8.425, p X^{2}(1, N=362)=11.751, p X^{2}(1, N=356)=8.838, p X^{2}(1, N=362)=4.704, p X^{2}(1, N=362)$ $=11.508 p X^{2}(1, N=362)=5.495, p X^{2}(1, N=359)=12.595, p<0.01$. Conclusion: This research suggests that paramedic programs conducting interdisciplinary simulation indicated they have greater access to resources and faculty training to support simulation.
\end{abstract}

\section{Author Bio(s)}

- Kim D. McKenna MEd, RN, EMT-P is Chair of the Research Committee at the National Association of EMS Educators, and Director of Education at St. Charles County Ambulance District

- Elliot Carhart EdD, RRT, NRP, NCEE is Associate Professor and Director at the Center for Healthcare Simulation Research at Jefferson College of Health Sciences

- Daniel L. Bercher PhD, NRP is Chairman and Associate Professor at the University of Arkansas for Medical Sciences

- Andrew E. Spain MA, EMT-P, NCEE is Director of Accreditation and Certification at the Society for Simulation in Healthcare

- John Todaro BA, RN, NRP, NCEE is EMS/CME Academic Department Coordinator at St. Petersburg College

- Joann Freel BS, CMP is the Executive Director at National Association of EMS Educators

\section{Authors}

Kim D. McKenna, Elliot Carhart, Daniel Bercher, Andrew E. Spain, John Todaro, and Joann Freel 


\title{
IJAHSP \\ The Internet Joư⿱n一⿰口乚一al of Allied Health Sciences and Practice
}

Dedicated to allied health professional practice and education

Vol. 14 No. 2 ISSN 1540-580X

\section{Interprofessional Simulation in Accredited Paramedic Programs}

\author{
Kim McKenna, MEd, RN, EMT-P1 \\ Elliot Carhart, EdD, RRT, NRP, NCEE ${ }^{2}$ \\ Daniel Bercher, PhD, NRP3 \\ Andrew Spain, MA, EMT-P, NCEE ${ }^{4}$ \\ John Todaro, EdD, RRT, NRP, NCEE ${ }^{5}$ \\ Joann Freel, BS, CMP6
}

1. St. Charles County Ambulance District

2. Jefferson College of Health Sciences

3. University of Arkansas for Medical Sciences

4. Society for Simulation in Healthcare

5. St. Petersburg College

6. National Association of EMS Educators

\section{United States}

\begin{abstract}
Purpose: Healthcare leaders advocate for interprofessional education as a means to promote collaborative practice, enhance interdisciplinary communication, and improve patient safety in the health professions. There is little evidence specific to interprofessional simulation in paramedic education. Methods: The National Association of EMS Educators (NAEMSE) surveyed paramedic programs that were accredited or in the process of becoming accredited. Program respondents were asked to characterize their resources and their use of those resources, and then were asked about their perceptions pertaining to simulation in their program. Chi-square analysis was used to compare characteristics of programs that participated in interdisciplinary simulation with those that did not. Results: Of the 389 of 638 (61\%) paramedic program survey respondents, 44\% (159 of 362) report interprofessional simulation. They perceived they used the right amount of simulation more frequently than other paramedic programs $X^{2}(1, N=362)=8.425, p<0.01$. These programs indicated they have personnel support for simulation above regular faculty hours more often than those that did not $X^{2}(1, N=362)=11.751, p<0.01$. They also more frequently reported their simulation equipment was adequate $X^{2}(1, N=356)=8.838, p<.01$, and they more frequently use advanced (fully programmable) manikins $X^{2}$ $(1, N=362)=4.704, p<.05$, computer-based simulation $X^{2}(1, N=362)=11.508 p<0.01$, and virtual reality simulation $X^{2}(1, N=362)$ $=5.495, p<.05$ than programs that did not participate in interprofessional simulation. Interdisciplinary simulation programs were also more likely to report that faculty training was adequate $X^{2}(1, N=359)=12.595, p<0.01$. Conclusion: This research suggests that paramedic programs conducting interdisciplinary simulation indicated they have greater access to resources and faculty training to support simulation.
\end{abstract}

\section{INTRODUCTION}

As health systems transform to meet emerging community needs, the need for interprofessional education is growing. Globally, healthcare leaders advocate for interprofessional education as a means to promote collaborative practice, enhance interdisciplinary communication, and improve patient safety in the health professions. ${ }^{1-3}$ Simulation is an educational tool that can be used to hone such knowledge, skills, and practice within diverse clinical teams. ${ }^{4}$ There is little evidence specific to interprofessional simulation in paramedic education. Research involving medical, nursing, and other healthcare learners found that students with prior interprofessional learning experience had significantly more positive attitudes towards aspects of teamwork and collaboration such as being a more effective member of a healthcare team, working together to solve problems, improving interdisciplinary relationships, viewing other professions in a positive manner, trusting and respecting those in other professions, and recognizing 
their own limitations. ${ }^{5,6}$ Despite the beliefs regarding benefits of using simulation for interprofessional learning, McGaghie et al excluded interprofessional simulation from their list of simulation best practices because they felt there was insufficient research on this topic to include it. ${ }^{7}$

EMS professionals provide care to nearly 20 million patients annually in the United States. ${ }^{8}$ Paramedics practice at the "intersection between public health, healthcare, and public safety,"9 This broad role definition, coupled with the reality that EMS personnel pick up and deliver their patients virtually anywhere, means they interact often with personnel in these and many other disciplines. These interactions often involve critical, time sensitive situations. These factors mean that prehospital emergency care, much like emergency medicine, is ripe for conflict and error. ${ }^{10}$

Despite the benefits articulated above, there remain challenges to using simulation effectively in EMS. Faculty training, personnel resources, and equipment availability have been found to impede simulation use in accredited paramedic programs. ${ }^{11}$ These findings were similar in nursing where barriers to simulation included faculty training, cost, equipment issues, personnel resources, scheduling, and curricular issues. ${ }^{12}$ Interprofessional simulation has additional challenges such as scheduling, class size, program proximity, administrative buy-in, faculty resistance, regulatory limitations and scope of practice boundaries. ${ }^{1}$

Existing research related to interprofessional education in EMS suggests that participating in education with other health or public safety personnel increases understanding of other health professions' roles, how the role of each team member is central to how the health care team members collaborate to promote effective patient outcomes, and interprofessional competence. ${ }^{12,13}$ As described here, interprofessional competence refers to skill in communication, collaboration, roles and responsibilities, collaborative patient, and family-centered approach to care, conflict management, and effective team functioning. After participating in interdisciplinary education, paramedic students reported positive attitudes toward interprofessional cooperation. ${ }^{14}$ Currently, the literature is void of any investigations regarding the relationships between interdisciplinary simulation education and faculty training, resources, or faculty perceptions in entry-level paramedic programs.

\section{Methods}

A subcommittee of the National Association of EMS Educators' (NAEMSE) Research Committee conducted a planned secondary analysis of existing data from the Simulation Use in Paramedic Education Research (SUPER) project. ${ }^{11}$ The research proposal was determined to be exempt from further review by the Institutional Review Board of the University of Missouri - St. Louis.

This study utilized a census survey of all 638 paramedic programs that were accredited or had a letter of review from the Committee on Accreditation of Educational Programs for the Emergency Medical Services Professions (CoAEMSP) as of November 13, 2013. The CoAEMSP is the committee affiliate with the Commission on Accreditation of Allied Health Education Programs (CAAHEP) responsible for managing the paramedic program accreditation process (www.caahep.org). ${ }^{15} \mathrm{~A}$ letter of review designates that the paramedic program is in the "becoming accredited" process.

The 56 question survey instrument was developed and revised using a consensus group approach with the National Council for State Boards of Nursing (NCSBN) survey as a launching point to develop the research instrument. ${ }^{16}$ The survey was piloted within the research team and with eight additional paramedic programs. The principal investigator conducted cognitive interviews with the pilot sites to assure understanding of the survey questions and the committee later revised the survey instrument based on the findings from cognitive interviews.

\section{Results}

There were 389 valid survey responses (61\% response rate). The program location was categorized using the Federal Emergency Management Agency (FEMA) regions to protect the confidentiality of individual programs. ${ }^{16}$ More than half of paramedic programs responded from all Federal Emergency Management Agency (FEMA) regions except for region IV (southeast) which yielded just under a $50 \%$ response.

Post-secondary institutions constituted the largest group of responses (75\%) with two-year colleges comprising more than threequarters $(77 \%)$ of that group, followed by four-year college or university $(13 \%)$, technical schools $(9 \%)$, and other $(1 \%)$. The remaining institutional sponsorship types included hospital, clinic or medical center $(12 \%)$, consortium $(6 \%)$, governmental education or medical service (fire or EMS agency) (4\%), and other (3\%)

Program length ranged from 3 to 45 months $(M=13.38, S D \pm 5.06)$. Total average annual student enrollment varied widely; however $63 \%$ of programs had between 11 and 35 students enrolle $\bar{d}$ annually. Likewise, average individual class cohort size was between 11 and 35 students for $81 \%$ of the programs.

(c) The Internet Journal of Allied Health Sciences and Practice, 2016 
Preliminary analysis was conducted to control for the influence of extraneous demographic variables. This revealed no statistically significant difference in the frequency of interprofessional simulation and the type of institution sponsor, or sponsoring institution status (public, private: for profit, private: not-for-profit), or the program length or size.

There were 362 of the original 389 programs that replied to the interprofessional simulation questions. Of those, $159(44 \%)$ report simulation activities with other disciplines. These paramedic programs engaged in simulation with a broad range of disciplines, although nursing programs constituted the greatest number (Table 1).

Table 1. Disciplines Participating in Simulation with Paramedic Students

\begin{tabular}{|l|l|}
\hline Discipline & $\mathbf{n}(\%)$ \\
\hline Nursing & $128(81 \%)$ \\
\hline Medicine (e.g. MD, DO) & $58(36 \%)$ \\
\hline Law enforcement & $54(34 \%)$ \\
\hline Respiratory therapy & $54(34 \%)$ \\
\hline Mid-level providers (e.g. NP, PA) & $40(25 \%)$ \\
\hline Fire personnel & $11(7 \%)$ \\
\hline Emergency Medical Technicians & $10(6 \%)$ \\
\hline Radiology & $9(6 \%)$ \\
\hline
\end{tabular}

Note: Respondents also reported simulation participation with drug counseling, mental health, physical therapy, surgical technologist, day care, 911 dispatchers, health information, pharmacy technology, and veterinary technology programs.

Respondents were asked to describe their perception of the amount of simulation used in their programs (we should use more; we should use less; or we use the right amount). No program responded they should use less simulation and only $22 \%$ indicated they used the right amount of simulation. Programs reporting the use of interprofessional simulation responded that they used the right amount of simulation more frequently than did other programs $X^{2}(1, N=362)=8.425, p<0.01$.

A theme of significant findings emerged with regard to program resources in those programs that conduct interprofessional simulation as compared to their counterparts. Programs were asked to report how much personnel support they have for their simulation programs above regular faculty hours. There was a significant difference in personnel support for simulation $X^{2}(1$, $N=362)=11.751, p<0.01$, with programs that participate in interprofessional simulation, indicating they have more personnel support for simulation than those that did not.

These programs also more frequently indicated their simulation equipment was adequate $X^{2}(1, N=356)=8.838, p<0.01$ and they more frequently use advanced (fully programmable) manikins $X^{2}(1, N=362)=4.704, p<0.05$, computer-based simulation $X^{2}(1$, $N=362)=11.508 p<0.01$, and virtual reality simulation $X^{2}(1, N=362)=5.495, p<0.05$ than programs that did not participate in interprofessional simulation.

This trend toward more program resources for simulation continued in the area of faculty training. Interdisciplinary simulation programs also differed from those that did not when reporting that faculty training was adequate $X^{2}(1, N=359)=12.595, p<0.01$. More of the programs that conduct interprofessional simulation indicated their faculty training was adequate.

\section{Discussion}

At the time of this investigation, less than one-half of accredited paramedic programs reported that they participate in simulationrelated activities with other disciplines. No relationship between school characteristics and the frequency of interprofessional simulation was found in this study. Other factors contributing to the low use are unknown. Paramedic programs that participate in interprofessional simulation do so primarily with nursing and other health or public safety professions. Given the nature of paramedicine, this diversity in simulation partners is desirable and supports the need to provide interprofessional education.

This research suggests that paramedic programs involved in interdisciplinary simulation indicated they have greater access to personnel resources and faculty training to support simulation. These programs are also more likely to use more complex technological types of simulation such as advanced (fully programmable) manikins, computer-simulation, and virtual reality simulation. No differences related to the type of school emerged, but it would seem logical that programs that participate in interprofessional simulation have a system and resources in place that lower the barriers known to exist with this type of simulation. While it is reasonable to suspect that this might simply be associated with the sharing of resources among those who participate in interprofessional simulation, our previous results showed that in general, programs that had access to advanced (fully programmable) manikins used them less frequently than programs who had their own. ${ }^{11}$

(C) The Internet Journal of Allied Health Sciences and Practice, 2016 
This study is limited by its design and therefore does not capture whether paramedic programs participate in interprofessional activities more frequently because of the training and personnel resources they have or if such participation facilitates their access to these resources. Further, it is unclear if these factors are associated with the greater satisfaction they report regarding the amount of simulation used in their programs. Additional qualitative research in this area might better identify programmatic differences that inhibit and facilitate interprofessional simulation.

\section{Conclusion}

The benefits of interprofessional education and simulation have been demonstrated in other fields, but such practices have not previously been described in the context of paramedic education. Nonetheless, the use of interprofessional simulation as a learning strategy seems to be a desirable goal for paramedic education, given the dynamic nature of paramedicine and the various other professionals with which paramedics must interact during the course of their duties. This study provides an important primer for a topic that has the potential to influence academic outcomes among paramedic students.

There are several known inherent difficulties associated with interprofessional simulation and so it is hardly surprising that this study found this strategy is more likely to be used in programs with adequate equipment, faculty training, and personnel resources for simulation. Program administrators should recognize the need to establish an underlying simulation infrastructure for student participation in interprofessional simulation activities. This can allow for meaningful, context-based learning that will benefit the students, their patients and the healthcare community.

\section{REFERENCES}

1. Palaganas JC, Mancini ME. Interprofessional education using clinical simulations. In Jeffries RP (Ed.), Clinical Simulations in Nursing Education: Advanced Concepts, Trends, and Opportunities. Philadelphia, PA: Wolters Kluwer Lippincott, Williams \& Wilkins; 2014:58-70.

2. Frenk J, Chen L, Bhutta ZA, Cohen J, Crisp N, Evans T, et al. Health professionals for a new century: transforming education to strengthen health systems in an interdependent world. Lancet. 2010 Dec; 376(9756); 1923-58. [PMID: 21112323]

3. Bradley P. The history of simulation in medical education and possible future direction. Med Educ. 2006 Mar; 40(3):254-62. [PMID: 16492228]

4. Gaba DM. The future vision of simulation in health care. Qual Saf Health Care. 2004 Oct; 13 (Suppl 1):i2-10. doi:10.1136/qshc.2004.009878. [PMID: 15465951]

5. Hood K, Cant R, Baulch J, Gilbee A, Leech M, Anderson AS, Davies K. Prior experience of interprofessional learning enhances undergraduate nursing and healthcare students' professional identity and attitudes to teamwork. Nurs Educ Pract. 2014 Mar; 14(2):117-122. [PMID: 23937910]

6. McFadyen AK, Webster V, Strachan K, Figgins E, Brown H, McKechnie J. The readiness for interprofessional learning scale: A possible more stable sub-scale model for the original version of RIPLS. J Interprof Care. 2005 Dec; 19 (6):595-603. [PMID: 16373215]

7. McGaghie WC, Issenberg SB, Barsuk JH, Wayne DB. A critical review of simulation-based mastery learning with translational outcomes. Med Educ. 2014 Apr; 48 (4):375-85. [PMID: 24606621]

8. U.S. Department of Transportation, National Highway Traffic Safety Administration. National EMS Workforce Agenda for the Future, 2011. (DOT HS 811 473). Washington, DC: Accessed August 30, 2015 at http://www.ems.gov/pdf/2011/EMS_Workforce_Agenda_052011.pdf

9. American College of Emergency Physicians. EMS as an essential public safety service. Clinical \& Practice Management: ACEP Policy Statement, 2010. Accessed February 22, 2015 at http://www.acep.org/Clinical---Practice-Management/EMSas-an-Essential-Public-Safety-Servicel

10. Croskerry P, Sinclair D. Emergency medicine: A practice prone to error? Canadian Journal of Emergency Medicine. 2001 Oct; 3 (4):271-6. [PMID: 17610769] Accessed August 30, 2014 at http://www.cjem-online.ca/v3/n4/p271

11. McKenna KD, Carhart E, Bercher D, Spain A, Todaro J, Freel J. Simulation use in paramedic education research (SUPER): a descriptive study. Prehosp Emerg Care. 2015 Jul-Sep; 19 (3):432-40. doi: 10.3109/10903127.2014.995845. [PMID: 25664774]

12. McKenna L, Boyle M, Palermo C, Molloy E, Williams B, Brown T. Promoting interprofessional understanding through online learning: a qualitative examination. Nurs Health Sci. 2014 Sep; 16 (3):321-6. doi: 10.1111/nhs.12105. [PMID: 2440496]

13. Riesen E, Morley M, Clendinneng D, Ogilvie S, Ann Murray M. Improving interprofessional competence in undergraduate students using a novel blended approach. J Interprof Care. 2012 Jul; 26 (4):312-8. [PMID: 22559163]

14. Williams B, Webb V. Examining the measurement properties of the Interdisciplinary Education Perception Scale (IEPS) in paramedic education. Nurse Educ Today. 2013 Sep; 33 (9):981-5. [PMID: 23159166]

15. Committee on Accreditation of Educational Programs for the Emergency Medical Service Professions. CoAEMSP; 2014.

(c) The Internet Journal of Allied Health Sciences and Practice, 2016 
Accessed August 30, 2015 at www.coaemsp.org.

16. Hayden J. Use of simulation in nursing education: National survey results. J Nurs Regul. 2010; 1:52-7.

17. Federal Emergency Management Agency. Regional Operations. Accessed August 30, 2014 at www.fema.gov/regionaloperations. 